\title{
The association between influenza vaccination and socioeconomic status in high income countries varies by the measure used: a systematic review
}

Kelsey Lucyk ${ }^{1}$, Kimberley A. Simmonds ${ }^{1,2}$, Diane L. Lorenzetti ${ }^{1,3}$, Steven J. Drews ${ }^{4,5}$, Lawrence W. Svenson ${ }^{1,2,6}$ and Margaret L. Russell ${ }^{1 *}$ (i)

\begin{abstract}
Background: The purpose of this paper is to systematically review the literature on the relationship between socioeconomic status (SES) and influenza immunization and to examine how certain measures of SES may influence interpretations of this relationship.

Methods: We conducted a systematic review of existing peer-reviewed literature to evaluate the above relationship in the general population. Electronic databases (MEDLINE and EMBASE) were searched from January 2012 to May 2017 to identify English-language studies relevant to this review. Studies were included where influenza vaccination was explicitly reported as the dependent variable and SES as the independent variable. We limited our review to measures of SES that focus on education, income, social class, occupation, and deprivation. Studies that measured SES using other variables (e.g., race, ethnicity, geographic location, rural or urban status, or insurance status) were excluded. Studies were also excluded if they did not report on the human population or did not analyze original data. The population of interest included all age groups, levels of health status, and sociodemographic backgrounds. The review was also limited to World Bank high-income countries. Two authors independently screened full-text articles after obtaining a Kappa score of $K=0.867$. The methodological quality of manuscripts was assessed using the appraisal tools developed by the Joanna Briggs Institute. Results were qualitatively reported and synthesized.

Results: Of the 42 articles included in this review, $52.4 \%(n=22)$ found that higher levels of SES resulted in higher levels of influenza vaccination; $4.5 \%(n=2)$ reported a negative association; and 14.3\% $(n=6)$ found no association. Just over a quarter $(26.2 \%, n=12)$ of articles reported mixed results.

Conclusions: There was consistently a relationship between SES and influenza immunization, which varied according to how SES was measured. It is recommended that authors be explicit in defining the SES concept they are trying to capture and that they utilize multiple measures of SES (e.g., education, income, class).
\end{abstract}

Keywords: Influenza, Vaccination, Socioeconomic status

\footnotetext{
* Correspondence: mlrussel@ucalgary.ca

${ }^{1}$ Department of Community Health Sciences, Cumming School of Medicine,

University of Calgary, 3280 Hospital Dr NW, Calgary, AB T2N 3Z6, Canada

Full list of author information is available at the end of the article
}

(c) The Author(s). 2019 Open Access This article is distributed under the terms of the Creative Commons Attribution 4.0 International License (http://creativecommons.org/licenses/by/4.0/), which permits unrestricted use, distribution, and reproduction in any medium, provided you give appropriate credit to the original author(s) and the source, provide a link to the Creative Commons license, and indicate if changes were made. The Creative Commons Public Domain Dedication waiver (http://creativecommons.org/publicdomain/zero/1.0/) applies to the data made available in this article, unless otherwise stated. 


\section{Background}

Worldwide, public health authorities have implemented vaccination programs targeting groups at high-risk of morbidity and mortality for influenza. The World Health Organization (WHO) recommends annual vaccination for pregnant women, children between the ages of 6 months to 5 years, the elderly over the age of 65 years, individuals with chronic medical conditions, and healthcare workers [1]. In some jurisdictions, influenza vaccination is provided at low-cost or no-cost (out of pocket) to certain individuals. Canada offers universal coverage for medically necessary health care services (i.e., "universal publicly funded healthcare") [2]. As of 2018, 10 of Canada's 13 provinces and territories provide the vaccine free of charge to all residents; the remainder offer free vaccine to targeted high-risk groups [3].

The relationship between socioeconomic status (SES) and health is well-documented worldwide for a number of outcomes [4], including those related to influenza. Disparities in influenza-related hospitalizations and deaths may occur in certain populations where social determinants of health influence an individual's exposure to a disease, their risk behaviours, or their options for treatment and prevention [5]. Surveillance data in the United States (US) have shown higher rates of influenza hospitalizations in areas with high levels of poverty, population density, crowded housing conditions, and female-headed households $[5,6]$.

As Nagata et al. (2013) found in a systematic review on the association between social determinants of health and seasonal influenza vaccination in the elderly population, the direction of the association between vaccination and SES varies [7]. The authors found that elderly persons from higher SES backgrounds sometimes had higher rates of vaccinations (e.g., in areas where policies and programs had been implemented to increase vaccination among vulnerable and high-risk groups), but not always [7]. Given the mixed findings reported by the above review, there is a need to revisit the literature regarding the relationship between SES and influenza vaccination with respect to the general population, including children, adults, and the elderly.

There is a lack of consensus in the literature on how SES should be measured [8]. SES is a complex social, economic, and political concept that cannot be measured directly. Instead, SES is measured indirectly by using the proxy measures of class (e.g., economic resources), prestige (e.g., community ranking), occupation (e.g., occupational class), and/or education (e.g., education level) $[9,10]$. We anticipate that the different ways of measuring SES may mask or intensify associations between SES and vaccination status and that associations may differ depending on whether the vaccine is universally available and publicly funded.
The purpose of this review was first to systematically review and synthesize the literature to answer the following research question: Is there a relationship between SES and influenza immunization status? Second, we wished to determine to what extent specific measures used to capture SES influenced the relationship between SES and influenza immunization status.

\section{Methods}

\section{Protocol and eligibility criteria}

We searched the literature to identify quantitative studies where the outcome measure was influenza vaccination and the independent variable was SES. The PRISMA guidelines for reporting systematic reviews have been followed throughout this manuscript [11]. The study protocol for this review has not been previously published or registered [11].

\section{Information sources}

We searched OVID Embase and Ovid MEDLINE databases from January 2012 to May 2017 to identify relevant studies. We consulted a medical librarian to develop the search strategy.

\section{Search}

Searches were developed that combined terms from two themes: SES (occupation, income, education, employment, class, or social and material deprivation) [8] and influenza immunization (influenza, immunization, immunisation, vaccine, vaccination). Terms were searched as both title/abstract words and database-specific subject headings (Additional file 1). The search included only empirical English-language articles published from January 2012 to May 2017. No study design filters were applied.

\section{Study selection}

Two authors (KL, MLR) independently screened abstracts in duplicate for eligibility. Using a sample of eligible articles, these authors developed a full-text review sheet to reach agreement on article inclusion from a sample of 15 articles $(K=0.867)$. Following this, one author $(\mathrm{KL})$ independently screened full-text articles for inclusion. Studies were not excluded on the basis of summary measures used (e.g., odds ratios, means), provided that they quantitatively reported vaccination rates by SES level. Studies were included where: 1 ) the primary outcome was influenza vaccination, measured in any way (e.g., self-report, administrative records, health records) as a dependent variable; 2) SES was an independent variable, explicitly defined, and expressed as social class, socioeconomic status, socioeconomic position, occupational class, educational attainment, income, poverty, deprivation index, neighbourhood-based measures 
(e.g., postal code to show deprivation areas), and/or employment status (Fig. 1); and 3) studies reported on data from World Bank high-income countries [12]. Studies were excluded if they: 1) did not report influenza vaccination as the primary outcome or independent variable; 2) did not report on the human population; 3) were not published in the English language; 4) did not explicitly state the SES measure used; 5) did not measure SES as outlined above; 6) used SES to assess only for effect measure modification or confounding; 7) did not analyze original data; 8) did not have a comparison group, if an analytic study; or, 9) did not concern a World Bank high-income country. The reference lists of included articles were hand-searched to identify relevant articles that met the search and inclusion criteria.

\section{Data extraction}

Two authors (KL, MLR) developed a data extraction form, which one author (KL) used to extract data from the included studies. Data included: the population (e.g., age group, health status, sex), intervention (e.g., SES concept used, measure of SES, level of SES measure used, analysis, strength of association), comparison group (e.g., unvaccinated adults), study details (e.g., study purpose, study design, data source used), setting (e.g., country, year data collected, city), and results (e.g., findings on the association between influenza vaccination and SES). For each association reported, we recorded the variables that study authors adjusted for in their analysis, such as age and sex. Many studies adjusted for numerous "sociodemographic variables" in their multivariable analyses, which, as described in the legend of Tables 1, 2 and 3, included age, sex, place of residence, education level, and rural residence. Tables 1, 2 and 3 also report details on study findings, summary measures, and the level of significance for each association found.

\section{Risk of bias across studies}

The methodological quality of included studies was independently assessed two authors (KL, MLR) using

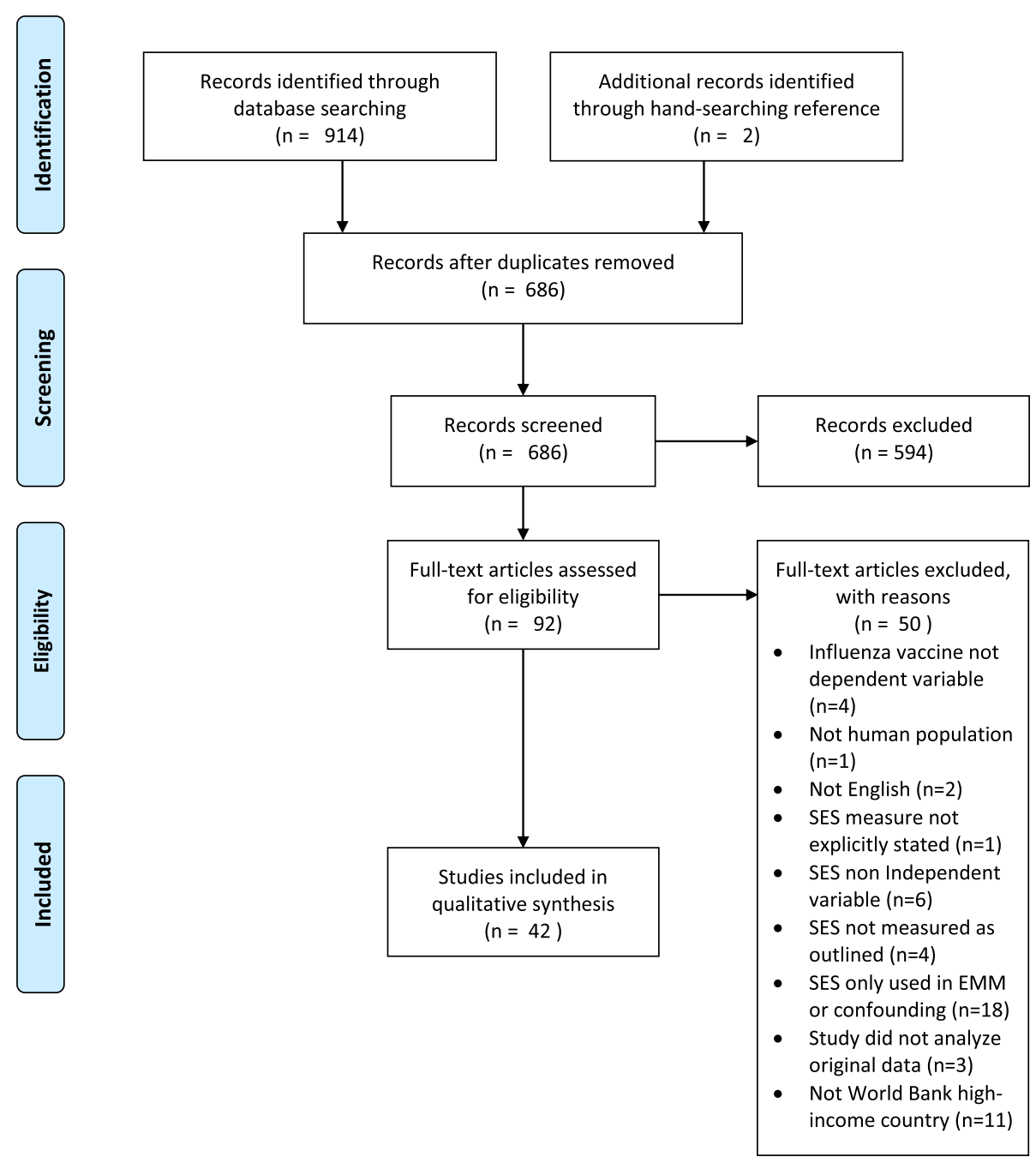

Fig. 1 PRISMA flow diagram of study selection 


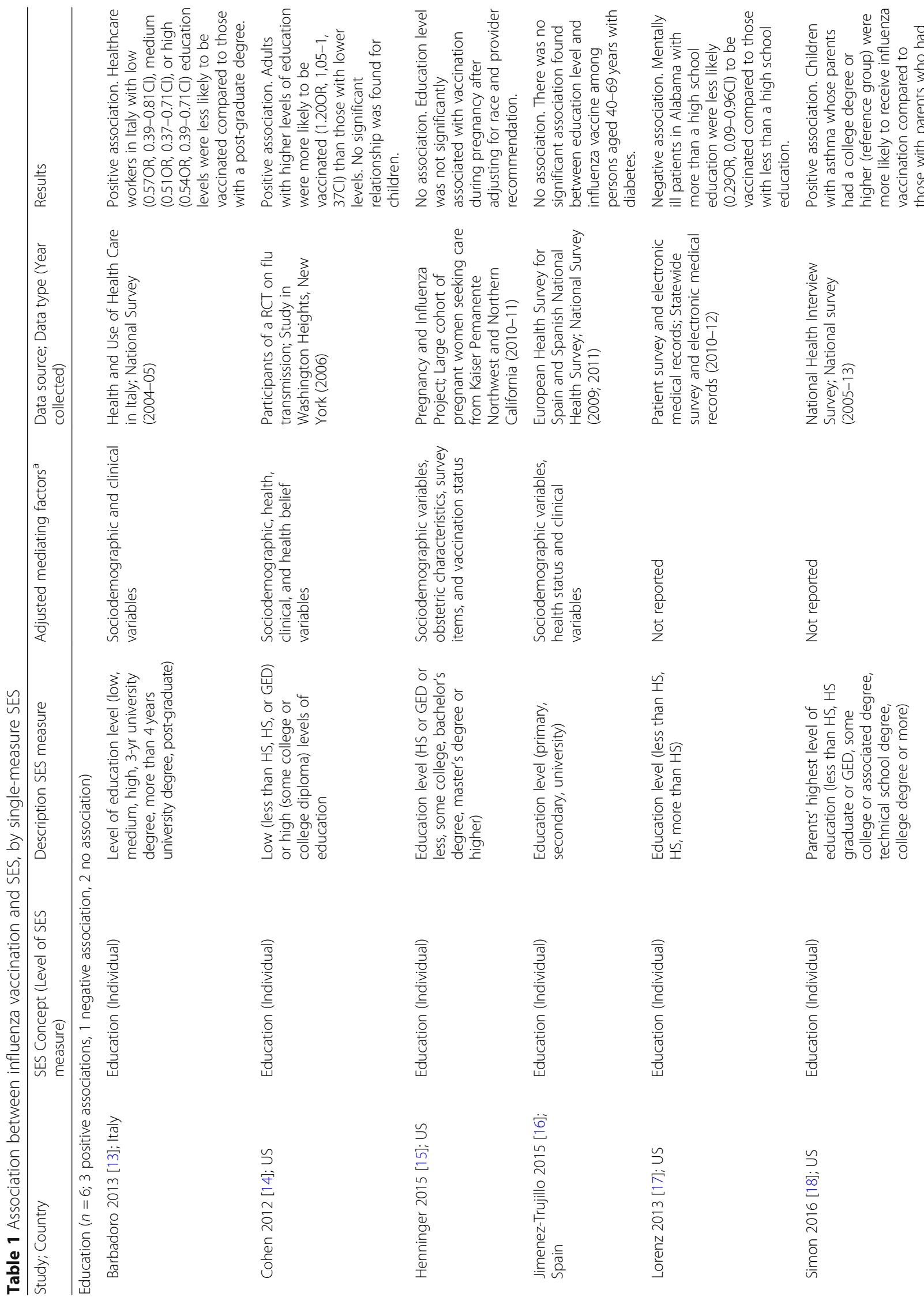




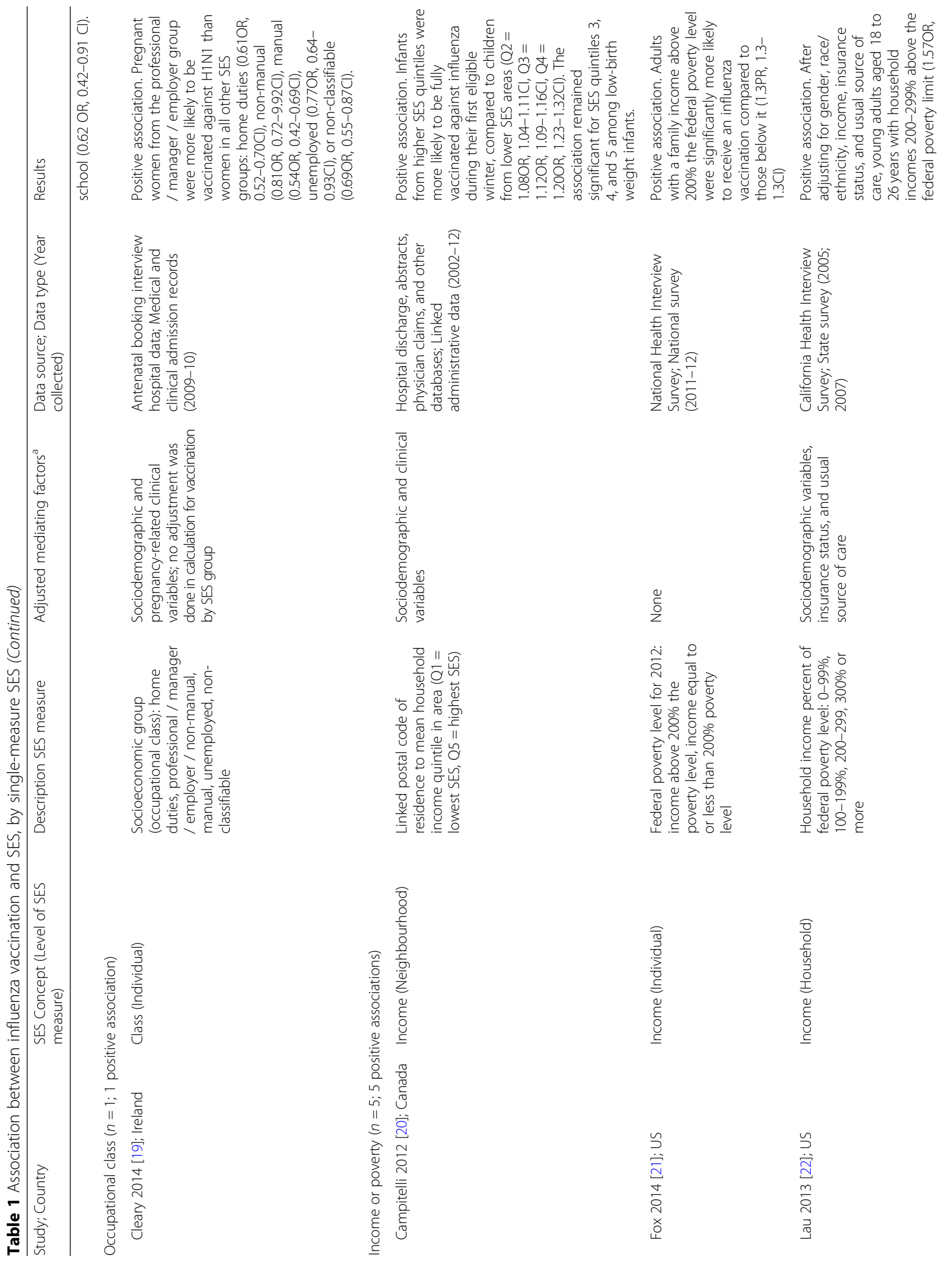


Lucyk et al. BMC Medical Research Methodology

(2019) 19:153

Page 6 of 23

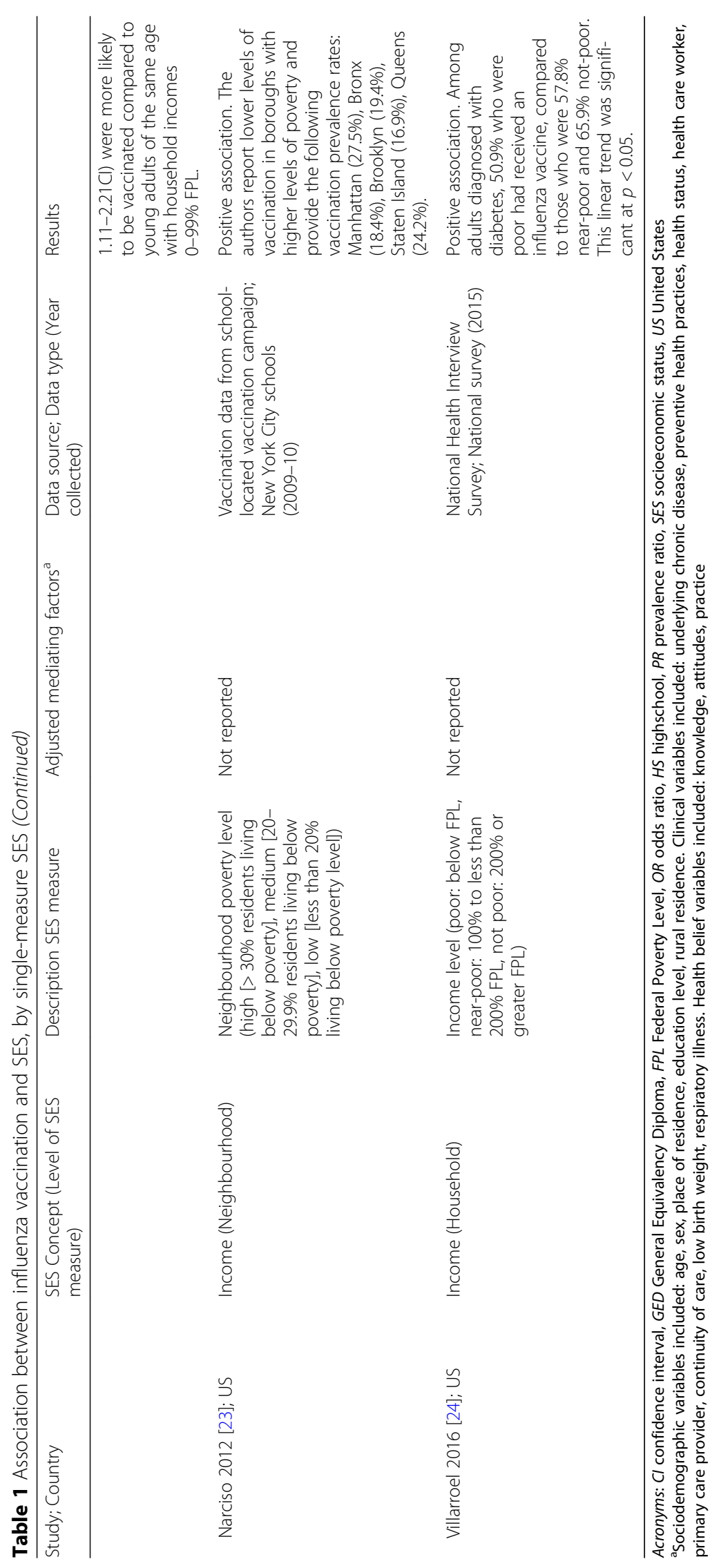




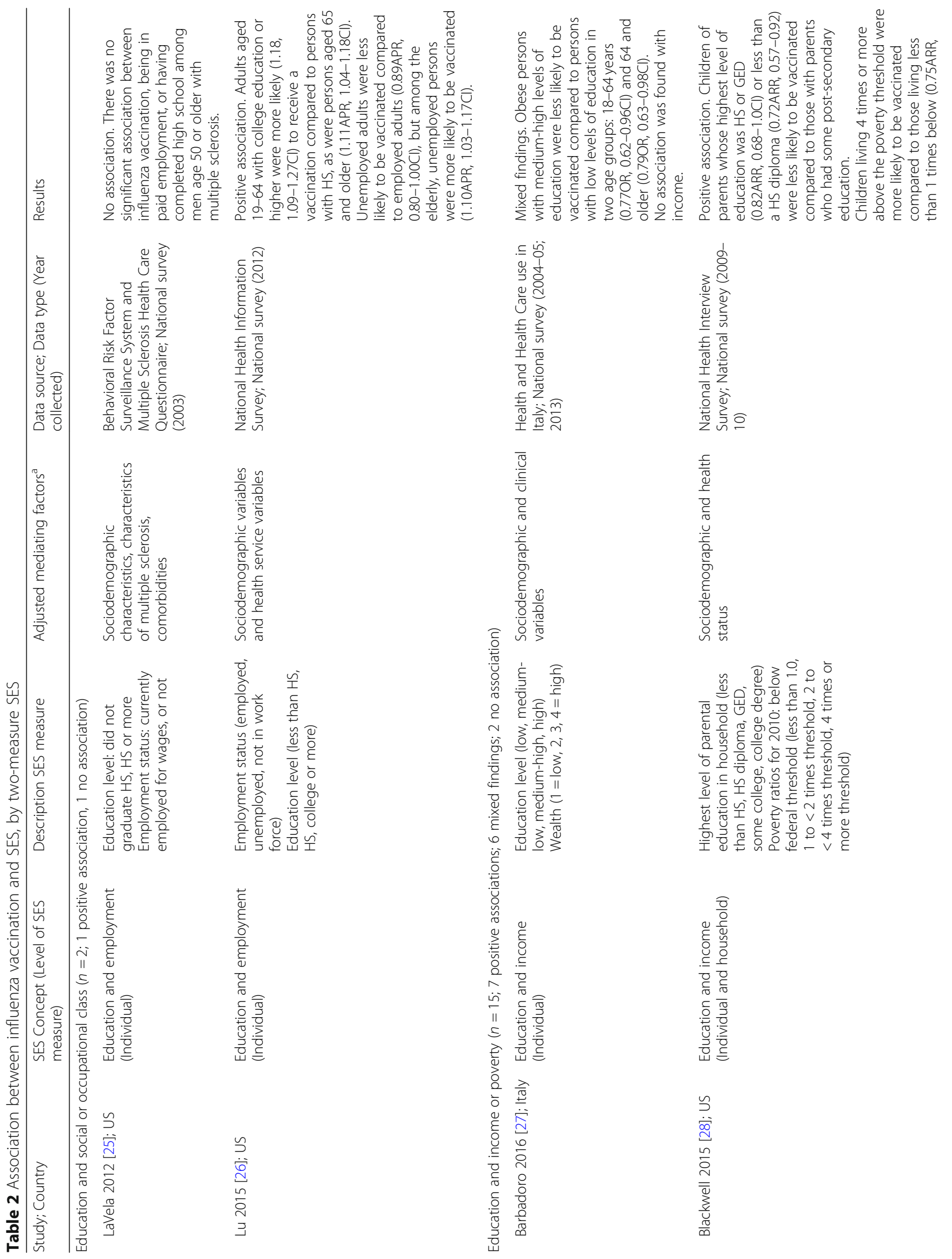




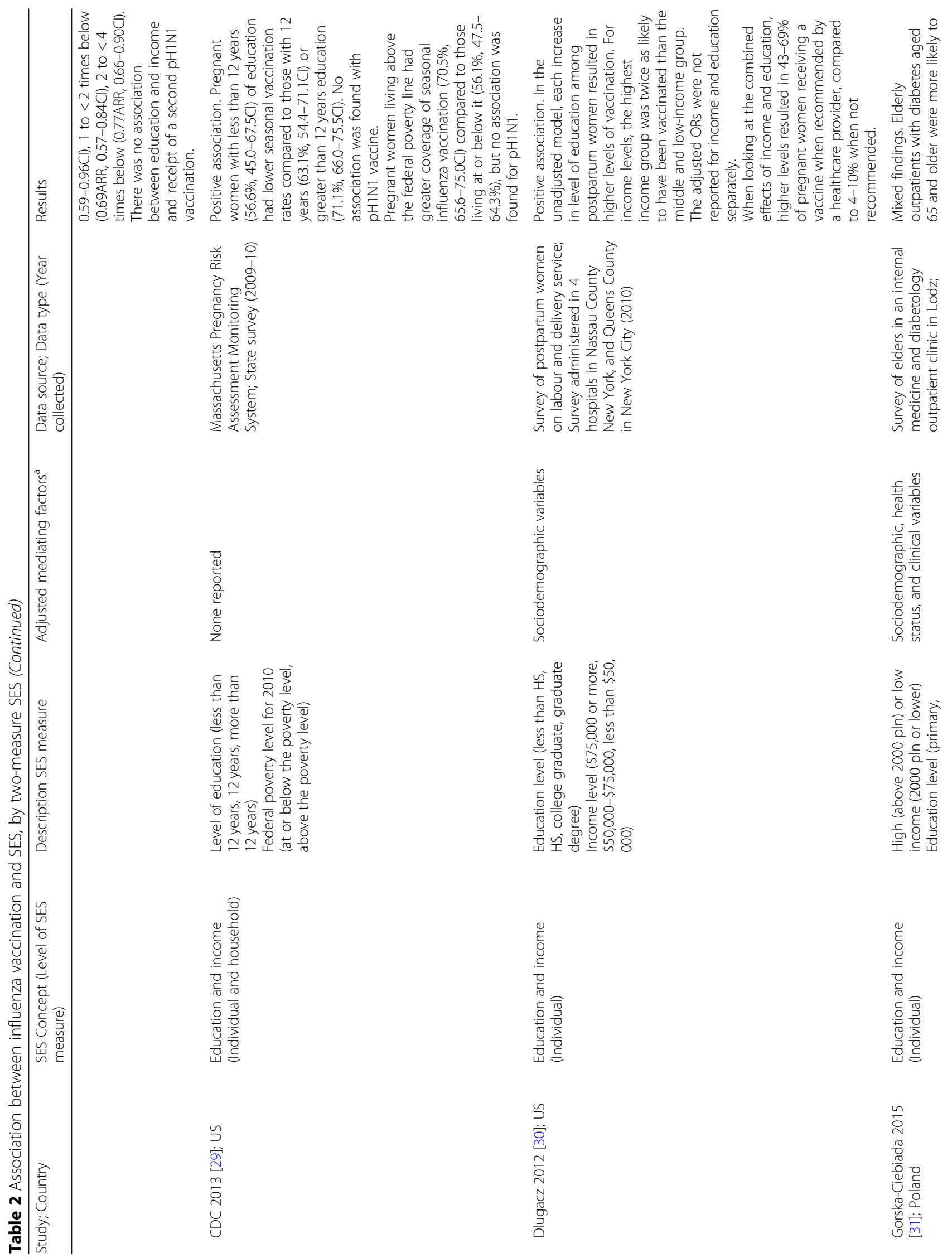




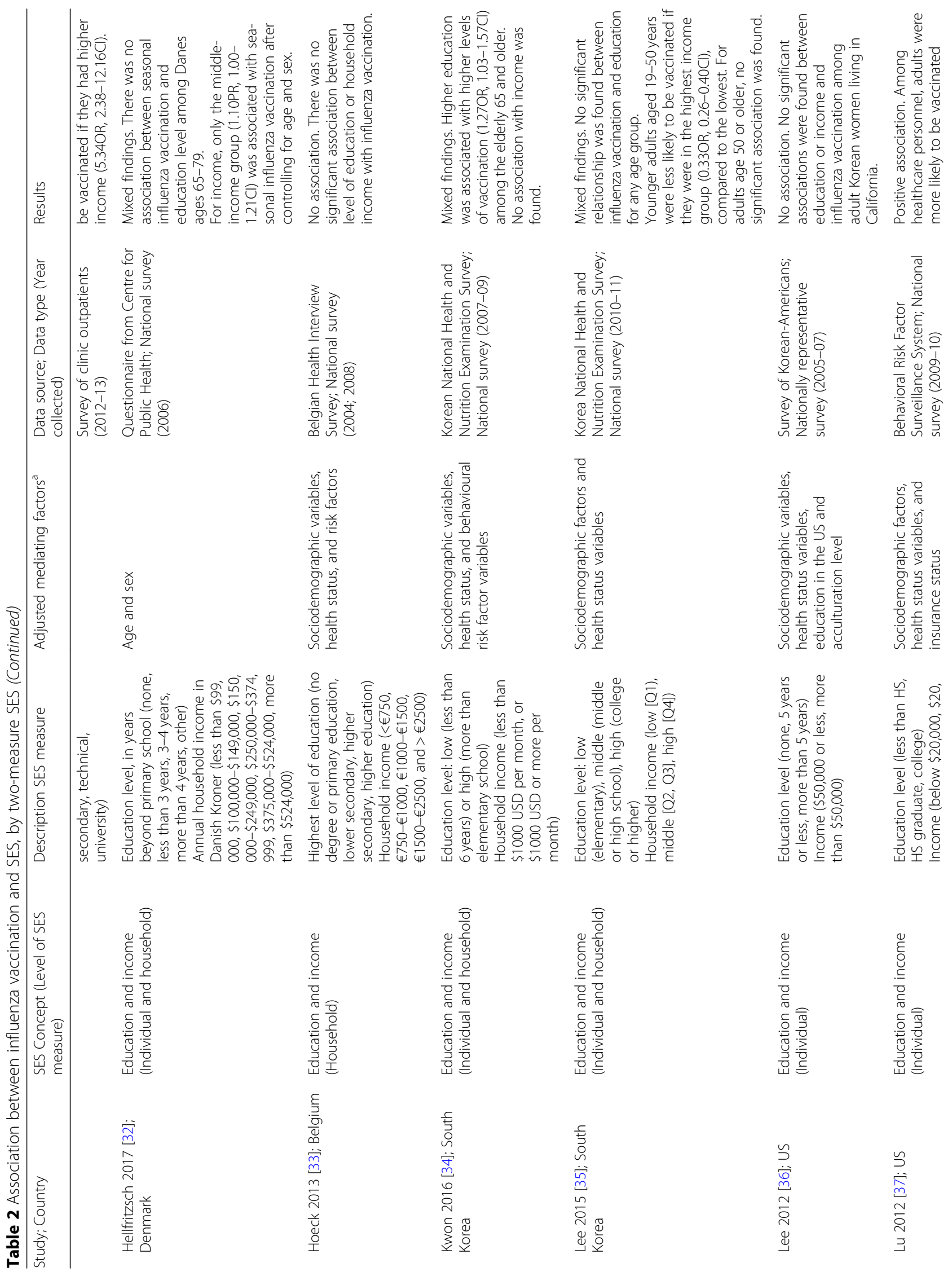




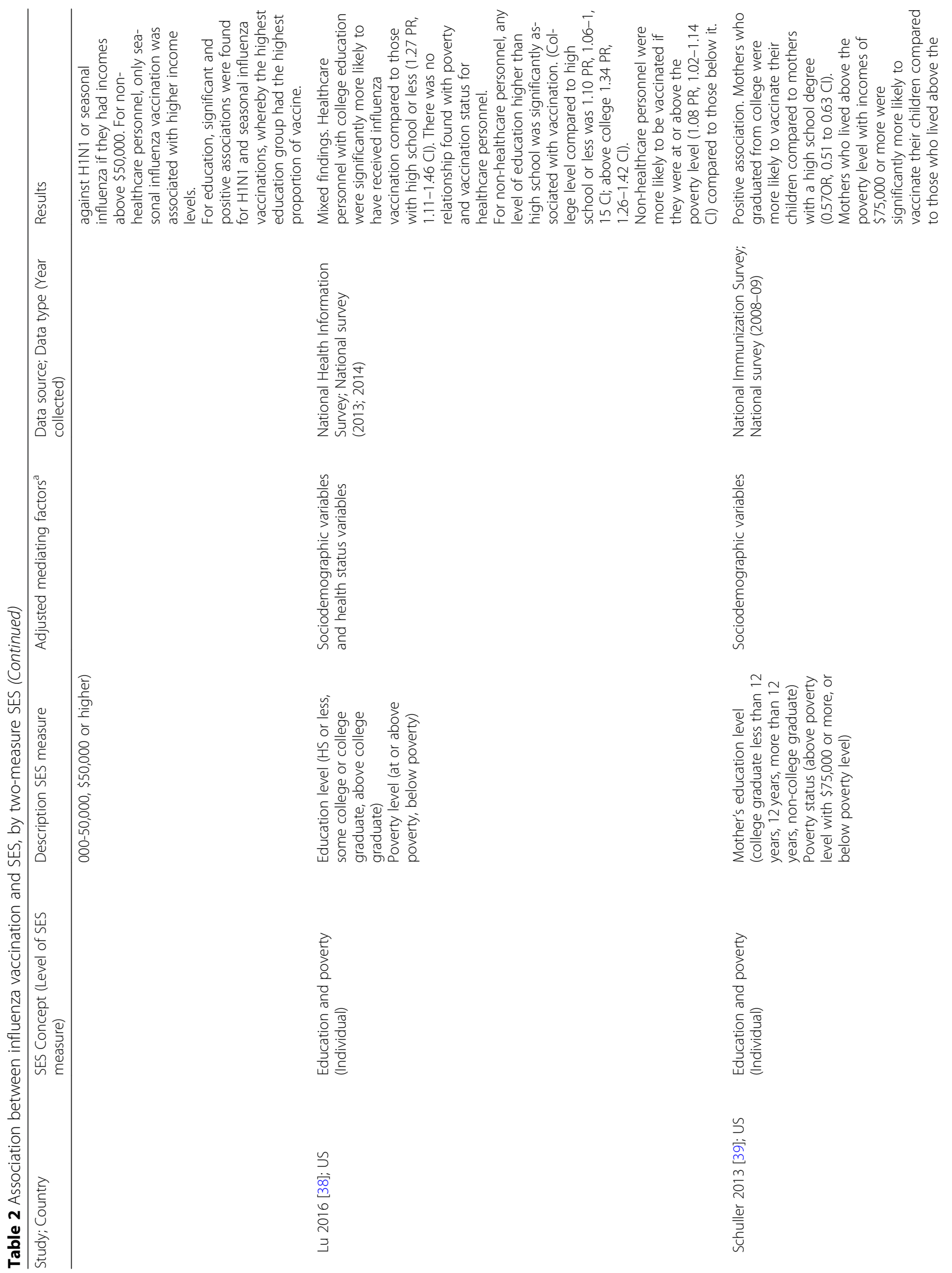




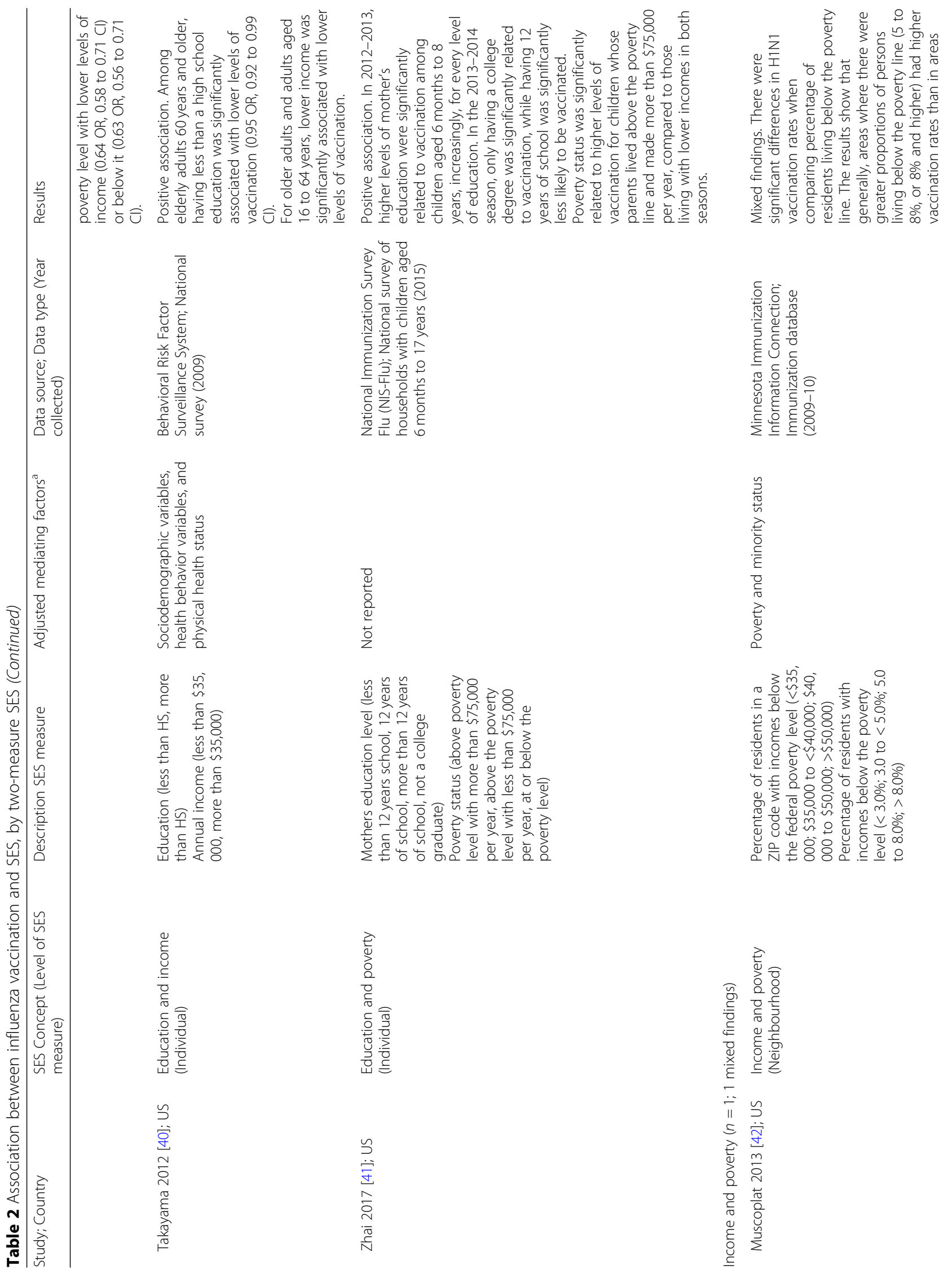




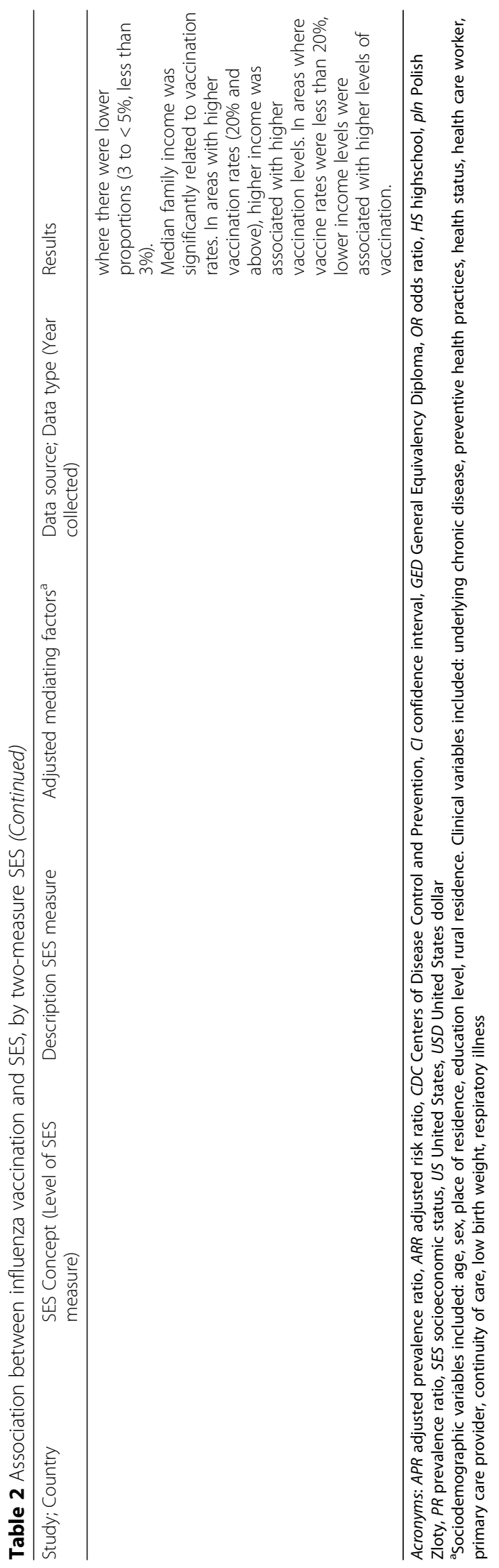




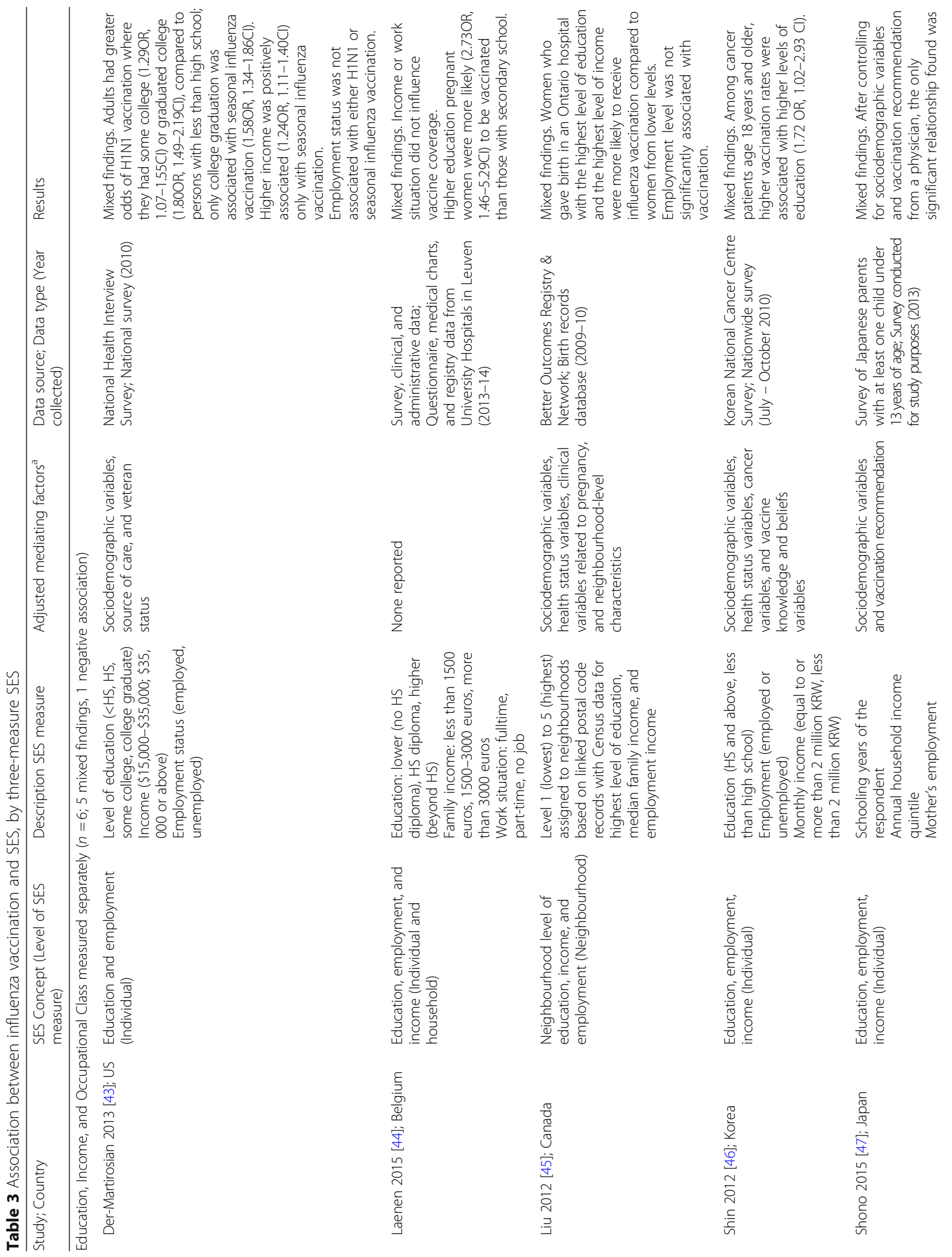




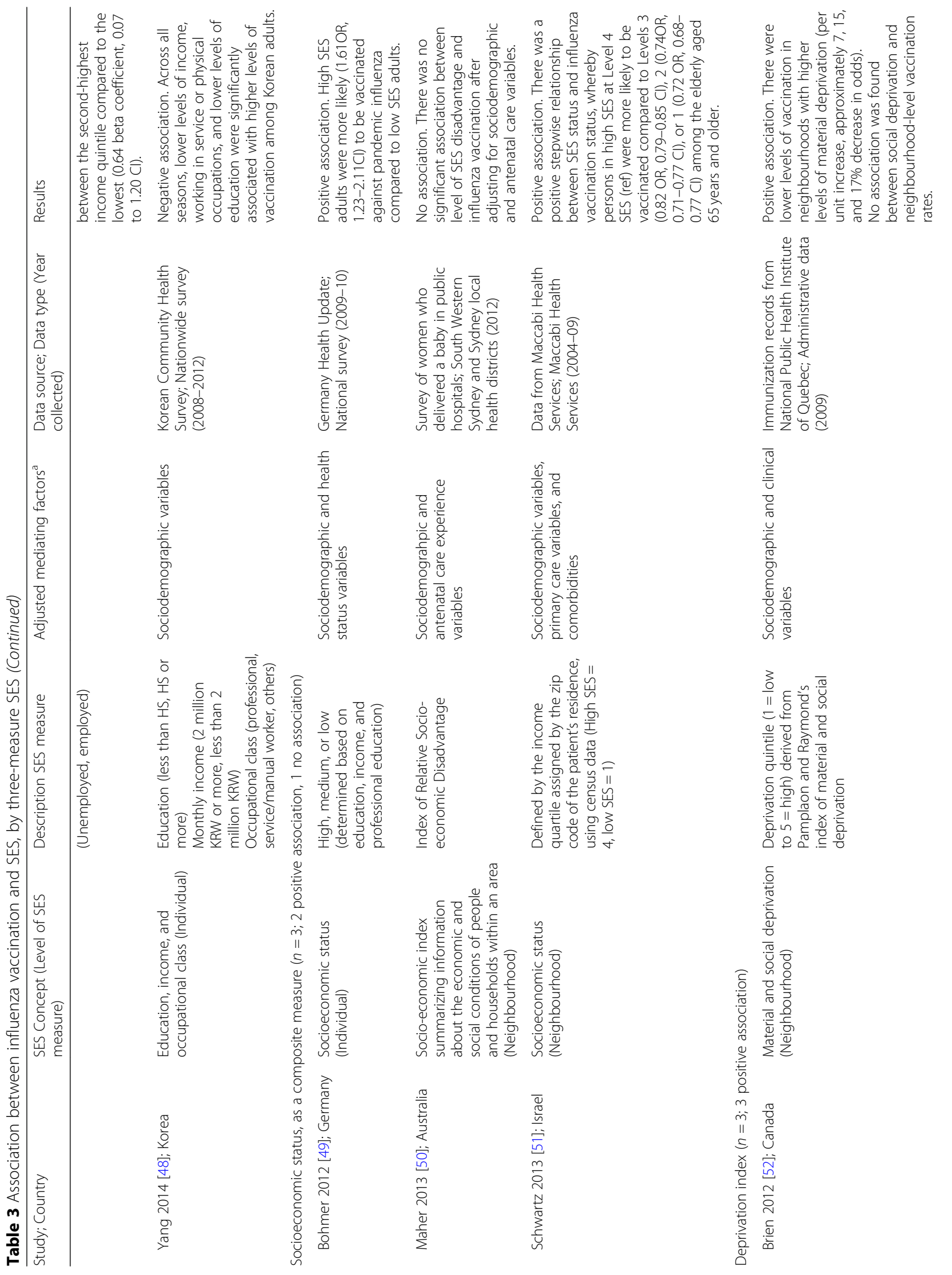


Lucyk et al. BMC Medical Research Methodology

(2019) 19:153

Page 15 of 23

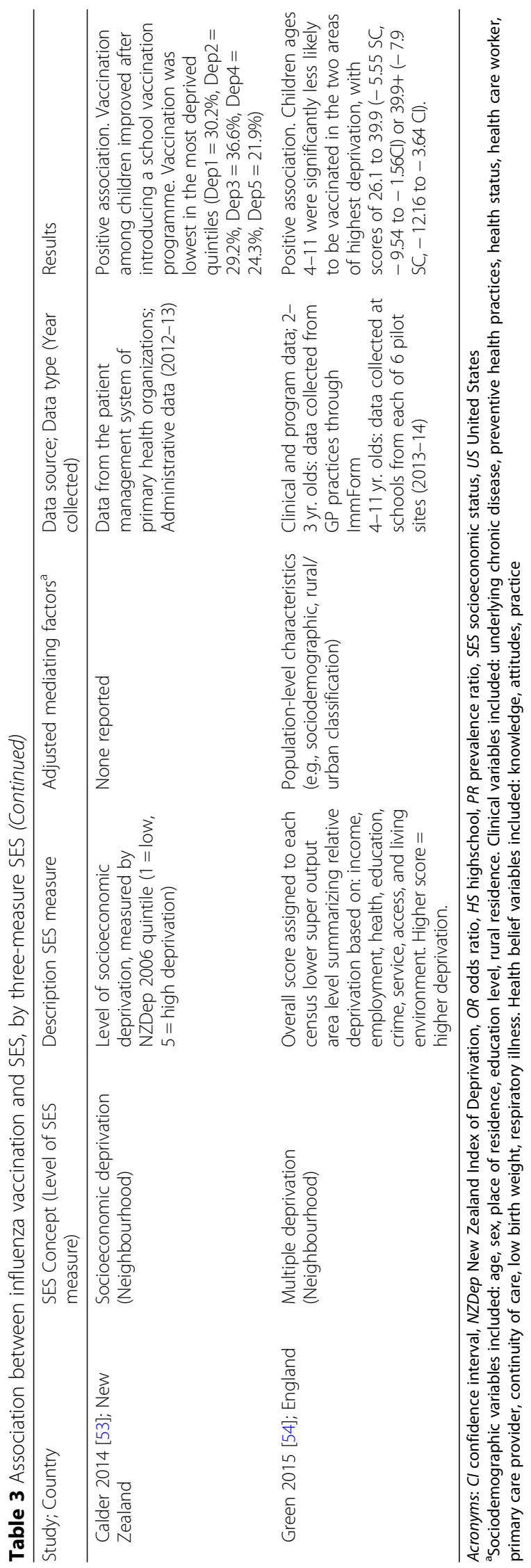


critical appraisal tools developed by the Joanna Briggs Institute (JBI) for prevalence studies [55], analytical cross-sectional studies [56], and cohort studies [57]. It was decided that manuscripts would not be excluded based on their methodological quality, though the authors considered a manuscript to be of adequate quality where it received a minimum score of six out of nine, five out of eight, or seven out of 9,8 , or 11 (depending on the checklist), based on the experiences reported by others [58].

\section{Synthesis of results}

A narrative summary of studies was completed. Study heterogeneity precluded the completion of a metaanalysis.

\section{Results}

A total of 914 records were identified from the above search strategy, which resulted in 686 unique abstracts after the removal of duplicates. Five-hundred and ninety-four abstracts were excluded in the abstract review stage, leaving 92 articles for full-text review. Of these, 42 were synthesized and included in this review (Fig. 1).

\section{Study characteristics}

Of the 42 studies that assessed the relationship between influenza vaccination and SES, 40 (95.2\%) were descriptive or exploratory and two $(4.8 \%)$ were analytical. Thirty-three studies $(78.6 \%)$ were cross-sectional, five (11.9\%) were ecological, and four $(9.5 \%)$ were cohort studies.

Included studies predominantly came from the US $(50.0 \%, n=21)$, followed by South Korea $(9.5 \%, n=4)$, Canada $(7.1 \%, n=3)$, Belgium $(4.8 \%, n=2)$, Italy $(4.8 \%$, $n=2)$, and others $(2.4 \%, n=1$ each from Australia, Denmark, England, Germany, Ireland, Israel, Japan, New Zealand, Poland, and Spain). Articles focused on a range of age groups. The majority focused on adult populations, defined as ranging from 18 to 65 years $(38.1 \%, n=$ $16)$, or the general population $(31.0 \%, n=13)$. Other categories included children under 18 years $(19.0 \%, n=8)$ and the elderly over 65 years $(11.9 \%, n=5)$ of age. Specific subsets of populations included healthcare workers, parents, pregnant or postpartum women, or patients with diabetes, obesity, or multiple sclerosis.

\section{Risk of bias across studies}

For the 37 studies assessed using the JBI Critical Appraisal Checklist for Prevalence Studies, the data quality scores were nine $(100 \%)$ for 13 studies, eight $(88.9 \%)$ for 17 studies, 7 (77.8\%) for 4 studies, $6(66.7 \%)$ for 2 studies, and 3 (33.3\%) for 1 study. All four studies assessed using the JBI Critical Appraisal Checklist for Analytical
Cross-Sectional Studies scored eight (100\%). The single study assessed using the JBI Critical Appraisal Checklist for Cohort Studies received a data quality score of 10 (90.9\%) out of 11. Disagreements on methodological quality were resolved through discussion and joint assessment until consensus was reached. Detailed results from quality assessments are provided in Additional files 2, 3, and 4.

\section{Relationship between SES and influenza vaccination}

Included studies reported positive associations, negative associations, no association, or mixed associations.

Just over half of studies $(52.4 \%, n=22)[13,14,18-24$, $26,28-30,37,39-41,49,51-54]$, reported a positive association between high SES (any individual or combination of education, income, or occupation) and increased influenza vaccination. Nine of the 22 studies (40.9\%) that reported positive associations used one measure to capture SES (e.g., education attainment level or household income level) [13, 14, 18-24], eight (36.4\%, $n=8)$ used two or more measures of SES [26, 28-30, 37, $39-41]$, and five $(22.7 \%, n=5)$ used a single, composite measure of SES that combined the effects of education, income, and occupational class for an area (e.g., neighbourhood deprivation level) [49, 51-54].

Only two studies $(4.8 \%)$ reported a negative association between SES and vaccination, where lower levels of education, income, or class resulted in higher rates of vaccination $[17,42,48]$. One of these studies reported a negative association using education only [17], while the other measured SES using a single composite measure that combined education, income, and occupational class [48].

Eleven studies (26.2\%) reported mixed results [27, 31, $32,34,35,38,42-47]$. All of the studies in this category used more than one measure to capture SES and reported inconsistent results on the association between influenza and SES. Seven studies used two measures $[27,31,32,34,35,38,42]$ and five studies used three measures or a composite measure combining three or more measures of SES [43-47].

Six studies (14.3\%) reported no association between SES and influenza vaccination. Of the six $[15,16,25,33$, $48,50]$, two used a single measure for SES $[15,16]$, three used two measures $[25,33,36]$, and one used a single composite measure of SES that combined the effects of multiple socioeconomic variables within a neighbourhood [50].

Relationship between SES measure and influenza vaccination We found that most studies $(n=30,71.4 \%)$ followed the recommended practice of measuring SES by using more than one measure of SES [8]. Twelve studies used three or more variables to measure SES; 18 used two variables 
to measure SES, using either a combination of education and income $(n=12)[27-37,40]$, education and poverty $(n=3)[38,39,41]$, education and employment $(n=2)$ $[25,26]$, or income and poverty $(n=1)$ [42]; and 12 used a single measure for SES using education $(n=6)$ [13-18], income or poverty $(n=5)$ [20-24], or occupational class $(n=1)$ [19]. Specific details about the associations reported for each measure are reported in the sections that follow.

\section{Single measures of SES}

Twelve of the 42 studies included in the review (28.6\%) measured the relationship between influenza vaccination and one measure for SES: education, occupational class, or income. Of the 6 studies that used education as a single measure, 3 found a positive association. All 5 studies measuring income or poverty reported positive associations. The single study on occupational class found a positive association (Table 1).

\section{Education (14.3\%, $n=6 / 42)$}

Barbadoro et al. (2013) conducted a cross-sectional survey of Italian healthcare workers, among whom they found that lower levels of education were significantly associated with lower levels of influenza vaccination when compared to healthcare workers with postgraduate degrees, after adjusting for sociodemographic and clinical variables [13]. Cohen et al. (2012) found in a repeated cross-sectional study of adults in Washington Heights, New York that adults with higher levels of education were more likely to be vaccinated, with no relationship found for children [14].

In Spain and the US, two studies focused on influenza vaccination and SES in patient populations. A crosssectional survey of Spanish adults with diabetes [16] found no significant association between levels of vaccination among persons with primary and secondary education after adjusting for age, sex, and other health and clinical variables. An historical cohort study of pregnant women ages 16 and older in Northern California [15], found an association between education and vaccination, where women with a master's degree or higher were more likely to have been vaccinated compared to women with high school or less; however, this association disappeared after researchers adjusted for sociodemographic and maternal characteristics, including race, age, and provider recommendation for vaccine. Lorenz et al. (2013) [17] found that, after adjusting for age, health perception, and behaviour variables, education was negatively associated with influenza vaccination in adult outpatients with mental illness in Alabama. Specifically, outpatients with more than a high school level of education were significantly less likely to be vaccinated when compared to those with less than a high school education (0.29 OR; 0.09-0.96 CI, $p<0.01)$ [17]. Simon et al. (2016) conducted a cross-sectional study among children aged two to 17 years with asthma in the US, using the parents' highest level of education as a measure of SES [18]. They found that children of parents with less education were significantly less likely to receive a vaccination as compared to those whose parents had at least one college degree (0.62 OR; $0.42-0.91 \mathrm{CI}$, $p<0.05)$ [18].

\section{Occupational Class (2.4\%, $n=1 / 42)$}

One historical cohort study of pregnant women in Dublin, Ireland found that during the H1N1 pandemic, women working in higher occupational classes (i.e., professional, manager, employer) were significantly more likely to be vaccinated compared to women working in any other occupation or who were unemployed (e.g., home duties, non-manual, manual, unemployed, nonclassable) [19].

\section{Income or poverty $(11.9 \%, n=5 / 42)$}

Five studies assessed the relationship between income and influenza vaccination. One cohort study from Ontario, Canada, determined that children from neighbourhoods with higher incomes were significantly more likely to be fully vaccinated against influenza than children from other areas [20]. Consistent with the above finding, an ecological study in New York City also found that children from neighbourhoods with higher levels of poverty had higher levels of H1N1 vaccination [23].

Fox and Shaw (2014), in a cross-sectional survey of the US general population, found that persons with higher family incomes were significantly more likely to have received an influenza vaccine [21]. Lau et al. (2013) likewise found higher income to be associated with significantly higher levels of vaccine in a cross-sectional survey of young adults aged 18 to 26 in California, though the association lost significance for income levels greater than $300 \%$ the federal poverty line [22]. Finally, Villarroel et al. (2016) found a positive association among US adults with diabetes, where vaccination levels were highest among the wealthiest of the sample [24].

\section{Two measures of SES}

Eighteen of the 42 studies (42.9\%) measured the relationship between influenza vaccination and SES using two measures (i.e., education and social or occupational class; education and income; education and poverty or income; income and poverty). Table 2 illustrates findings for all studies that used two measures to capture SES.

Education and social or occupational class $(4.8 \%, n=2 / 42)$

Two studies measured SES using a combination of education and social or occupational class. In the US, 
LaVela et al. (2012) found a positive relationship between being vaccinated and being employed or having more education in a national survey of men with multiple sclerosis [25]. Lu et al. (2015) also conducted a cross-sectional survey of the US adult general population and reported a consistent and significant positive association between higher education levels, employment, and vaccination status [26]. For adults over 65, unemployment was associated with higher vaccination rates [26].

\section{Education and income or poverty $(35.7 \%, n=15 / 42)$}

A cross-sectional survey of Italian adults found that obese persons aged 18 to 64 were significantly less likely to be vaccinated if they had completed high school, compared to those with only primary or intermediate schooling (0.77 OR; 0.62-0.96 CI, $p<0.05$ ) [27]. A similar association was found for obese persons aged 64 and older [27]. No association was found when SES was measured using wealth (i.e., as an indicator of social class) for either age group [27]. In the US, one crosssectional study of the general population found that children were significantly less likely to have received their first $\mathrm{pH} 1 \mathrm{~N} 1$ vaccination in households where the highest level of education was less than a college degree or where the household income was below four times the federal poverty line [28]. No relationship was found for the second pH1N1 vaccination. Schuller et al. (2013) found that children aged 19 to 35 months whose mothers had a college education or lived above the poverty level were significantly more likely to be immunized compared to those whose mothers had less education or lower levels of income [39]. Similarly, Zhai et al. (2017) reported that the likelihood of vaccination increased incrementally for US children aged 6 months to 8 years for each level of maternal education [41]. This association was found for the 2012-2013 flu season, but not for 2013-2014 [41]. Children from households with incomes greater than $\$ 75,000$ per year were significantly more likely to have been vaccinated in both flu seasons [41].

A cross-sectional study conducted by the US Centers for Disease Control and Prevention (2013) found that pregnant women in Massachusetts with higher levels of education or income had higher levels of seasonal influenza vaccination, but not $\mathrm{pH} 1 \mathrm{~N} 1$ vaccination [29]. In New York State, a cross-sectional survey of postpartum women 14 to 47 years found that those with a graduate degree and the highest incomes were most likely to have received an H1N1 vaccination, which was tied to a healthcare provider recommendation in as many as $69 \%$ of cases [30]. When the authors examined the combined effects of income and education, no significant association was found [30].
Two studies compared US healthcare workers' coverage to the general population. Lu et al. (2012) found that both populations were significantly more likely to receive $\mathrm{H} 1 \mathrm{~N} 1$ or seasonal influenza vaccination where they had higher levels of income and education [37]. In a similar study, researchers found that for healthcare workers and non-healthcare workers, higher levels of vaccination were significantly associated with having less than a high school level of education [38]. In addition, non-healthcare workers living at or above the poverty line were more likely to be vaccinated than persons below the poverty line [38].

In a cross-sectional survey of an elderly population with Type 2 diabetes in Lodz, Poland, Gorska-Ciebiada et al. (2015) found no significant association between education level and receipt of the 2012-2013 influenza vaccination [31]. However, adults with higher incomes ( $>2000$ Polish Zloty) were over five times as likely to be vaccinated than those with lower incomes [31]. A crosssectional survey of the elderly in Denmark found no significant relationship between seasonal influenza vaccination and education or income level [32]. The same was found among the Belgian elderly [33], even after adjusting for the effects of age, sex, sociodemographic variables, health status, and risk factors. In Korea, Kwon et al. (2016) reported a significant and positive association between vaccination levels and high levels of education among an elderly population (1.27 OR; 1.03-1.57 CI, $p=0.025)$ after adjusting for sociodemographic variables, health status, and behavioural risk factors, but no association between income and vaccination status [34].

Lee et al. (2015) conducted a cross-sectional survey among the general population in South Korea and stratified results by age group [35]. Among persons aged 50 and older, vaccination levels decreased as education levels and household income levels increased; this association was found to be insignificant upon adjusting for the effects of age, sociodemographic, residence, health, and other factors [35]. Among the younger population, education levels and vaccination were negatively associated, but not statistically significantly [35]. However in the same study, higher household income levels and vaccination were positively associated. Lee et al. (2012) surveyed Korean-American women living in California and found no association between either education or income and influenza vaccination [36].

Takayama et al. (2012) found that among the elderly in the US, higher levels of education were positively and significantly associated with vaccination, but not for adults aged 18 to 64 [40]. Both in the older and the younger age groups, participants were significantly more likely to be vaccinated where they had higher levels of income [40]. 


\section{Income and poverty (2.4\%, $n=1 / 42)$}

One ecological study compared $\mathrm{H} 1 \mathrm{~N} 1$ vaccination rates among Minnesota residents by using an area-based measure [42]. The authors (2013) found that areas with greater proportions ( $8 \%$ of more) of persons living below the poverty line had higher vaccination rates than areas with lower proportions (5-8\%)of persons living in poverty [42]. In areas where vaccination rates were low $(<20 \%)$, vaccination was associated with lower levels of family income [42]. In areas where vaccination rates were higher $(>/=20 \%)$, higher incomes were associated with vaccination [42].

\section{Income and class $(0 \%, n=0 / 42)$}

No studies measured SES using income and class.

\section{Three measures of SES}

Education, income, and class (28.6\%, $n=12 / 42)$

Twelve studies measured the relationship between vaccination and SES using measures for education, income, and class; half combined all three measures as a composite score to report SES as a single measure, and half analyzed the three measures separately. The findings from studies that use three measures to capture SES are synthesized in Table 3.

Three of the studies using composite scores were ecological studies, which all found that higher SES was significantly associated with higher levels of vaccination. One ecological study conducted in Montreal, Canada found that pandemic coverage decreased where there were greater levels of material and social deprivation [52]. After adjusting for sociodemographic and health variables, only material deprivation remained associated with vaccination coverage, particularly for pregnant women, chronically ill older persons, and healthcare workers [52]. Another ecological study evaluated the effects of a program for children under 18 in Canterbury, New Zealand [53]. They found that persons better off socioeconomically had higher levels of vaccination. Before the program, vaccination rates had been lower, but more equally distributed across deprivation quintiles. Another ecological study, conducted among English children 2 to 11 years, found that higher levels of deprivation resulted in lower levels of vaccination [54]. For children 4 to 11 years, this relationship was only significant for the two most deprived groups [54].

Three cross-sectional studies used composite measures of SES, two of which reported a significant and positive relationship with influenza vaccination. A survey of the German adult general population, found that higher socioeconomic status was significantly associated with seasonal influenza vaccination in the post-pandemic season [49]. In Israel, Schwartz et al. (2013), also found a positive and significant association between SES and influenza vaccine among the elderly [51]. Maher et al. (2013) found no association between vaccination and socioeconomic disadvantage among women who delivered a baby in public hospitals of Sydney, Australia after adjusting for sociodemographic, antenatal care, and experience factors [50].

Of the studies that employed three measures of SES to separately capture the effects of education, income, and employment or class, four reported mixed positive and negative associations and two reported consistent associations. Among US adults, Der-Martirosian et al. (2013) found that education level was positively associated with $\mathrm{H} 1 \mathrm{~N} 1$ and seasonal influenza vaccination, while income was only associated with seasonal influenza vaccination, and employment status was associated with neither [43]. In Leuven, Belgium, a survey of pregnant women in their third trimester found that only education was positively and significantly associated with vaccination [44]. A cohort study of pregnant women in Ontario, Canada found that higher neighbourhood levels of education, income, and employment were all associated with higher levels of influenza vaccination (though employment was not associated with statistical significance) [45]. A Japanese survey of parents with one or more children under 13 years found that only household income was significantly associated with seasonal influenza vaccination, even though the mother's employment and years of education were also included in the analysis [47].

Two studies of Korean populations both consistently reported associations across the separate measures of SES used. Among adult cancer patients, Shin et al. (2012) reported no significant association for employment, education, or income with vaccination [46]. Yang et al. (2014) found that vaccination levels were higher among persons with lower incomes, in non-professional occupations, and having less than a high school education across four flu seasons among adults 19 years and older [48].

\section{Public insurance status}

Seventeen studies considered whether public funding or insurance programs might influence the association between SES and influenza vaccination. In the US, individuals receive health coverage privately through an insurance plan, publicly through Medicaid (adults) or other programs, or are uninsured. One US study found a negative association, where pregnant Medicaid beneficiaries were less likely to receive an influenza vaccine [29]. Nine other US studies and one Irish study reported a positive association between having insurance and being vaccinated among children and youth [18, 22, 28, 39], adults [43], pregnant women [19, 30], healthcare personnel $[37,38]$, the elderly $[26,40]$, and mental health patients [17]. Overall, the literature seems to show that in countries without universal publicly-funded insurance, 
persons with private insurance were more likely to be vaccinated than persons receiving public insurance through social programs, and, those with public insurance were more likely to be vaccinated than those without any coverage. Five of the above nine US studies adjusted for the effects of other variables (including SES) in their analysis, four of which found insurance coverage to be independently associated with influenza vaccination. Three studies considered the role of influenza vaccination and SES in countries with tax-funded healthcare systems (i.e., Denmark [32], Belgium [33], and Spain [16]) and found no association.

\section{Discussion}

Over half of the studies included in this review support what has been reported previously: there is a relationship between SES and influenza vaccination. However, the direction of the relationship (i.e., positive or negative association) is not always clear and seems to vary depending on how SES is measured (e.g., as a single measure or a combination of education, income, class). The high numbers of positive associations likely reflect that nine of 42 studies (21.4\%) reported this relationship using a single measure to capture SES. It is possible that the association may not have been so prominent, had additional measures been used. To illustrate the above point, consider the following two studies, both which used the US National Health Interview Survey. In 2011, Fox and Shaw (2014) found that higher income was associated with higher levels of vaccination [21]. In 2010, Der-Martirosian et al. (2013) found an association between higher income and vaccination, but reported an association with only some levels of education, and no association with employment status [43]. It is possible that the 2011 study would have found similar findings, putting into question the potential influence of "SES," had they expanded their analysis.

Researchers may measure and report on SES depending on how they conceptualize this concept. Experts have recognized the implications that different measures of SES can have for healthcare policy and planning [59]. It is therefore important that authors employ as many measures as possible for SES and consider how they interact, to convey as much information about the influence of SES as possible.

In some cases, we found that while studies initially reported an association between SES and influenza, this association disappeared after adjusting for variables related to SES (e.g., age, sex, or rural location). One example is the relationship reported between education and influenza among pregnant women in California, which disappeared after the authors adjusted for race and healthcare provider recommendation [15]. These findings illustrate that factors other than SES may also affect the results and are important to consider in analysis due to their independent relationship with SES. For instance, individuals without public or private insurance may only access healthcare when they can afford to pay for it out of pocket. Similarly, individuals with higher levels of education may have access to jobs that afford them health insurance and access to healthcare providers.

Not all studies reported the variables that were adjusted for in the analysis, making it difficult to assess the true impact of SES on influenza vaccination. Experts have previously noted that SES is often employed as an adjustment variable in analysis to measure for potential confounding or effect measure modification [8], however, the above findings suggest it may be equally important to consider factors that are linked to SES less directly than income, education, and employment [60]. Additional factors that reflect an individual's social position, including working conditions, job security, and social support may mitigate access to quality education, adequate income levels, and meaningful work. Other factors such as race (and racism), ability (and ableism), gender (and gender-based discrimination), and social stigma may affect an individual's access to social and material resources.

Another variable linked to SES and influenza vaccination is insurance status, particularly in countries without universal, publicly-funded health care. We found that an overall positive relationship existed between persons with private health insurance and influenza vaccination in countries without universal, publicly-funded healthcare, but no association in countries with universal, publicly-funded health care. Studies from this review showed that private insurance was independently associated with influenza vaccination and SES, which suggests that its effects should be adjusted for during analysis as a potential confounder. Insurance status may serve as a marker of SES, since having private insurance may speak to the higher levels of skills or education that may be required to obtain well-paying, unionized, or other jobs likely to sponsor insurance plans for employees. Persons with health insurance may also be more likely to possess the financial and non-financial resources (e.g., transportation, time off work for appointments, health literacy, experience and trust in system) required to access healthcare. Some of the studies in this review have indicated that having a source of usual care and a physician that recommends influenza vaccination strongly influences whether individuals will receive immunization $[16,22,34]$. It is therefore recommended that authors explicitly address whether their study population is covered by publicly-funded health care or insurance programs when publishing on the topic of influenza vaccination and SES. 
Finally, the studies reviewed show variation among different populations. Healthcare personnel in the US were more likely to be vaccinated if they had higher levels of education [37, 38]; however, this may also reflect the presence of mandatory vaccination policies in some healthcare settings, such as hospitals. Another difference was the findings among the elderly, which often contradicted those for younger adults $[26,40]$. Trends in highrisk populations also differed from those in the general population. For example, while no association was found between income and vaccination for cancer patients in Korea or between education and vaccination among diabetic patients in Spain [16, 46]; a negative association was found between education and vaccination among obese patients in Italy [27]. It is possible that high-risk patients may be less affected by SES in situations where they receive regular care by a healthcare provider, which may - for populations with compromised immune systems - include a recommendation for vaccination.

There are limitations associated with this review. Studies were limited to the English language published between 2012 to 2017, which may have resulted in the exclusion of potentially relevant articles. A second limitation of this study is its focus on education, income, and class as determinants of SES. Other potential markers for SES include culture, race and ethnicity, knowledge, attitudes, and perceptions of the influenza vaccine, disability, and access to health care. Future research could focus on a broader assessment of SES to determine how the above factors mitigate the association between influenza vaccination and education, income, or class.

\section{Conclusion}

This comprehensive review has contributed additional knowledge about the relationship between SES and influenza vaccination. To the best of our knowledge, this is the first systematic review to explore this topic without limiting studies to a specific population by age or characteristic. We found that a relationship appears to exist across different patient and sociodemographic populations, internationally, and that this relationship varies according to which measures of SES are used. Further research is needed to consider how factors related to SES beyond education, income, and class influence the relationship between SES and influenza. Finally, we recommend that authors be explicit in describing the SES concept they are trying to capture with the measure(s) they use when they assess the association between SES and influenza vaccination. Where possible, we recommend that multiple measures of SES be utilized to tell as complete a story as possible.

\section{Additional files}

Additional file 1: Search strategies employed. This file contains the search strategies used for each database searched in the study. (DOCX 16 kb)

Additional file 2: Quality Assessment Results for Prevalence Studies (JBI Critical Appraisal Checklist for Studies Reporting Prevalence Data). A table reporting the results for each study assessed using the JBI Critical Appraisal Checklist for Studies Reporting Prevalence Data. (DOCX 35 kb)

Additional file 3: Quality Assessment Results for Analytical CrossSectional Studies (JBI Critical Appraisal Checklist for Analytical CrossSectional Studies) A table reporting the results for each study assessed using the JBI Critical Appraisal Checklist for Analytical Cross-Sectional Studies. (DOCX $18 \mathrm{~kb}$ )

Additional file 4: Quality Assessment Results for Cohort Studies (JBI Critical Appraisal Checklist for Cohort Studies) A table reporting the results for each study assessed using the JBI Critical Appraisal Checklist for Cohort Studies. (DOCX $20 \mathrm{~kb}$ )

\section{Abbreviations}

Cl: Confidence Interval; JBI: Joanna Briggs Institute; OR: Odds Ratio; SES: Socio-Economic Status; US: United States of America; WHO: World Health Organization

\section{Acknowledgements}

Not applicable.

\section{Authors' contributions}

All authors were involved in writing and revising the manuscript and provided final approval of the manuscript. KL, MLR, KAS, and SJD were responsible for the conception, with the inclusion of DLL and SJD involved in the study's design. $\mathrm{KL}$ and $\mathrm{DLL}$ completed data collection and assembly and $\mathrm{KL}$ provided administrative support. $\mathrm{KL}$ and MLR both completed data analysis and data interpretation, LWS contributed to data interpretation. All authors have read and approved the manuscript.

\section{Funding}

This study was funded by a research agreement between the University of Calgary and the Alberta Ministry of Health (RSO 1026380). The funding body had no role in the design of the study and collection, analysis, and interpretation of data or in writing the manuscript.

\section{Availability of data and materials}

The full search strategy is available in Additional file 1. The quality assessments of included studies are available in Additional files 2, 3, and 4.

Ethics approval and consent to participate Not applicable.

\section{Consent for publication}

Not applicable.

\section{Competing interests}

The authors declare that they have no competing interests.

\section{Author details}

${ }^{1}$ Department of Community Health Sciences, Cumming School of Medicine, University of Calgary, 3280 Hospital Dr NW, Calgary, AB T2N 3Z6, Canada. ${ }^{2}$ Alberta Ministry of Health, 10025 Jasper Avenue, Edmonton, AB T5J 1S6, Canada. ${ }^{3}$ Health Sciences Library, University of Calgary, 3330 Hospital Drive NW, Calgary, AB T2N 4N1, Canada. ${ }^{4}$ Medical Microbiology, Canadian Blood Services, 1800 Alta Vista Dr, Ottawa, ON K1G 4J5, Canada. ${ }^{5}$ Departments of Laboratory Medicine \& Pathology, University of Alberta, 8440 - 112 St, Edmonton, AB T6G 2J2, Canada. ${ }^{6}$ Division of Preventive Medicine \& School of Public Health, University of Alberta, Edmonton, 5-22F, University Terrace, 8303112 ST NW, Edmonton, AB T6G 1K4, Canada. 
Received: 20 July 2018 Accepted: 9 July 2019 Published online: 17 July 2019

\section{References}

1. World Health Organization. Influenza (seasonal). 2018 [Updated January 2018]. https://www.who.int/news-room/fact-sheets/detail/influenza(seasonal). Accessed 25 Feb 2018.

2. Government of Canada. Canada's health care system. Ottawa: Health Canada; 2018

3. Government of Canada. Public funding for influenza vaccination by province/territory. 2018 [Updated September 2018]. https://www.canada.ca/ en/public-health/services/provincial-territorial-immunization-information/ public-funding-influenza-vaccination-province-territory.html. Accessed 11 Mar 2019

4. World Health Organization (WHO) Commission on the Social Determinants of Health. Closing the gap in a generation: health equity through action on the social determinants of health. Final report of the Commission on Social Determinants of Health. Geneva: World Health Organization; 2008.

5. Sloan C, Chandrasekhar R, Mitchel E, Schaffner W, Lindgreen ML. Socioeconomic disparities and influenza hospitalizations, Tennessee, USA. Emerg Infect Dis. 2015; 21(9):1602-10.

6. Tam K, Yousey-Hindes K, Hadler JL. Influenza-related hospitalization of adults associated with low census tract socioeconomic status and female sex in New Haven County, Connecticut, 2007-2011. Influenza Other Respir Viruses. 2014;8(3):274-81

7. Nagata JM, Hernandez-Ramos I, Kurup AS, Albrecht D, Vivas-Torrealba C Franco-Paredes C. Social determinants of health and seasonal influenza vaccination in adults $\geq 65$ years: a systematic review of qualitative and quantitative data. BMC Public Health. 2013;13:388.

8. Oakes JM, Rossi PH. The measurement of SES in health research: current practice and steps toward a new approach. Soc Sci Med. 2003:56:769-84.

9. Berkman L, Macintyre S. The measurement of social class and health studies: old measures and new formulations. In: Kogevinas M, Pearce N, Susser M, Boffette $P$, editors. Social inequalities and cancer. Lyon: International Agency for Research on Cancer; 1997. p. 51-64.

10. Liberatos $P$, Link BG, Kelsey JL. The measurement of social class in epidemiology. Epidemiol Rev. 1998:10:87-121.

11. Liberati A, Altman DG, Tetzlaff J, Mulrow C, Gøtzsche PC, loannidis JP, et al. The PRISMA statement for reporting systematic reviews and meta-analyses of studies that evaluate health care interventions: explanation and elaboration. PLoS Med. 2009;6(7):e1000100

12. World Bank. World Bank country and lending groups. 2018. https:// datahelpdesk.worldbank.org/knowledgebase/articles/906519-world-bankcountry-and-lending-groups. Accessed 25 Mar 2018.

13. Barbadoro P, Marigliano A, Di Tondo E, Chiatti C, Di Stanislao F, D'Errico MM, et al. Determinants of influenza vaccination uptake among Italian healthcare workers. Hum Vaccin Immunother. 2013;9(4):911-6.

14. Cohen B, Ferng YH, Wong-McLoughlin J, Jia H, Morse SS, Larson EL. Predictors of flu vaccination among urban Hispanic children and adults. J Epidemiol Community Health. 2012:66(3):204-9.

15. Henninger ML, Irving SA, Thompson M, Avalos LA, Ball SW, Shifflett $P$, et al. Factors associated with seasonal influenza vaccination in pregnant women. J Womens Health. 2015;24(5):394-402.

16. Jimenez-Trujillo I, Jimenez-Garcia R, Esteban-Hernandez J, Hernandez-Barrera V, Carrasco Garrido PC, Salinero-Fort MA, et al. Predictors of adherence to multiple clinical preventive recommendations among adults with diabetes in Spain. PLoS One. 2015;10(6):e0131844

17. Lorenz RA, Norris MM, Norton LC, Westrick SC. Factors associated with influenza vaccination decisions among patients with mental illness. Int J Psychiatry Med. 2013;46(1):1-13.

18. Simon $A E$, Ahrens KA, Akinbami $\sqcup$. Influenza vaccination among US children with asthma, 2005-2013. Acad Pediatr. 2016;16(1):68-74.

19. Cleary BJ, Rice U, Eogan M, Metwally N, McAuliffe F. 2009 A/H1N1 influenza vaccination in pregnancy: uptake and pregnancy outcomes - a historical cohort study. Eur J Obstet Gynecol Reprod Biol. 2014;178:163-8.

20. Campitelli MA, Inoue M, Calzavara AJ, Kwong JC, Guttmann A. Low rates of influenza immunization in young children under Ontario's universal influenza immunization program. Pediatrics. 2012;129(6):e1421-e30.

21. Fox JB, Shaw FE. Relationship of income and health care coverage to receipt of recommended clinical preventive services by adults - United States, 2011-2012. MMWR Morb Mortal Wkly Rep. 2014;63(31):666-70.
22. Lau JS, Adams SH, Irwin CE, Ozer EM. Receipt of preventive health services in young adults. J Adolesc Health. 2013;52(1):42-9.

23. Narciso HE, Pathela P, Morgenthau BM, Kansagra SM, May L, Scaccia A, et al. Description of a large urban school-located 2009 pandemic H1N1 vaccination campaign, New York City 2009-2010. J Urban Health. 2012;89(2):317-28.

24. Villarroel MA, Vahratian A. Vaccination coverage among adults with diagnosed diabetes: United States, 2015. NCHS Data Brief. 2016;(265):1-8.

25. LaVela SL, Prohaska TR, Furner S, Weaver FM. Preventive healthcare use among males with multiple sclerosis. Public Health. 2012;126(10):896-903.

26. Lu PJ, O'Halloran A, Williams WW, Lindley MC, Farrall S, Bridges CB. Racial and ethnic disparities in vaccination coverage among adult populations in the U.S. Vaccine. 2015;33(Suppl 4):D83-91.

27. Barbadoro P, Recanatini C, Ponzio E, Illuminati D, D'Errico MM, Prospero E. Barriers to influenza vaccine uptake in obese people in Italy: changes 20052013. Eur J Intern Med. 2016:34:34-8.

28. Blackwell DL. Modeling receipt of influenza a(H1N1)pdm09 vaccinations among US children during the 2009-2010 flu season: findings from the 2010 National Health Interview Survey. Med Care. 2015;53(2):191-8.

29. Centers for Disease Control and Prevention. Influenza vaccination among pregnant women-Massachusetts, 2009-2010. MMWR Morb Mortal Wkly Rep. 2013;62(43):854-7.

30. Dlugacz Y, Fleischer A, Carney MT, Copperman N, Ahmed I, Ross Z, et al. $2009 \mathrm{H} 1 \mathrm{~N} 1$ vaccination by pregnant women during the 2009-10 H1N1 influenza pandemic. Am J Obstet Gynecol. 2012;206(4):339.e1-8.

31. Gorska-Ciebiada M, Saryusz-Wolska M, Ciebiada M, Loba J. Pneumococcal and seasonal influenza vaccination among elderly patients with diabetes. Postepy Hig Med Dosw. 2015:69:1182-9.

32. Hellfritzsch M, Thomsen RW, Baggesen LM, Larsen FB, Sorensen HT, Christiansen CF. Lifestyle, socioeconomic characteristics, and medica history of elderly persons who receive seasonal influenza vaccination in a tax-supported healthcare system. Vaccine. 2017;35(18):2396-403.

33. Hoeck S, van der Heyden J, Geerts J, Van Hal G. Preventive care use among the Belgian elderly population: does socio-economic status matter? Int J Environ Res Public Health. 2013;11(1):355-72.

34. Kwon DS, Kim K, Park SM. Factors associated with influenza vaccination coverage among the elderly in South Korea: the fourth Korean National Health and nutrition examination survey (KNHANES IV). BMJ Open. 2016; 6(12):e012618.

35. Lee KC, Han K, Kim JY, Nam GE, Han BD, Shin KE, et al. Socioeconomic status and other related factors of seasonal influenza vaccination in the south Korean adult population based on a nationwide cross-sectional study. PLoS One. 2015:10(2):e0117305.

36. Lee Y, Hofstetter CR, Irvin VL, Kang S, Chhay D, Reyes WD, et al. Korean American women's preventive health care practices: stratified samples in California, USA. Health Care Women Int. 2012;33(5):422-39.

37. Lu PJ, Ding H, Black CL. H1N1 and seasonal influenza vaccination of U.S healthcare personnel, 2010. Am J Prev Med. 2012:43(3):282-92.

38. Lu PJ, O'Halloran AC, Ding H, Williams WW, Black CL. Influenza vaccination of healthcare personnel by work setting and occupation - U.S., 2014. Am J Prev Med. 2016;51(6):1015-26.

39. Schuller KA, Probst JC. Factors associated with influenza vaccination among US children in 2008. J Infect Public Health. 2013;6(2):80-8.

40. Takayama M, Wetmore CM, Mokdad AH. Characteristics associated with the uptake of influenza vaccination among adults in the United States. Prev Med. 2012;54(5):358-62.

41. Zhai Y, Santibanez TA, Kahn KE, Srivastav A. Parental-reported full influenza vaccination coverage of children in the U.S. Am J Prev Med. 2017;52(4): e103-e13.

42. Muscoplat MH, Roddy M, Parilla E, Davey CS, Fleege L, White K, et al. 2009 H1N1 vaccination in Minnesota: an evaluation by ZIP code. Minn Med. 2013, 96(9):49-54.

43. Der-Martirosian C, Heslin KC, Mitchell MN, Chu K, Tran K, Dobalian A. Comparison of the use of $\mathrm{H} 1 \mathrm{~N} 1$ and seasonal influenza vaccinations between veterans and non-veterans in the United States, 2010. BMC Public Health. 2013;13:1082

44. Laenen J, Roelants M, Devlieger R, Vandermeulen C. Influenza and pertussis vaccination coverage in pregnant women. Vaccine. 2015;33(18):2125-31.

45. Liu N, Sprague AE, Yasseen IAS, Fell DB, Wen SW, Smith GN, et al. Vaccination patterns in pregnant women during the 2009 H1N1 influenza pandemic: a population-based study in Ontario, Canada. Can J Public Health. 2012;103(5):353-8. 
46. Shin DW, Kim Y, Park JH, Cho J, Jho HJ, Yang HK, et al. Practices and predictors of $2009 \mathrm{H} 1 \mathrm{~N} 1$ vaccination in cancer patients: a nationwide survey in Korea. Influenza Other Respir Viruses. 2012;6(6):e120-8.

47. Shono A, Kondo M. Factors associated with seasonal influenza vaccine uptake among children in Japan. BMC Infect Dis. 2015;15(1):72.

48. Yang $\mathrm{HJ}$, Cho SI. Influenza vaccination coverage among adults in Korea: 2008-2009 to 2011-2012 seasons. Int J Environ Res Public Health. 2014 11(12):12162-73.

49. Bohmer MM, Walter D, Falkenhorst G, Muters S, Krause G, Wichmann O. Barriers to pandemic influenza vaccination and uptake of seasonal influenza vaccine in the post-pandemic season in Germany. BMC Public Health. 2012; 12:938.

50. Maher L, Hope K, Torvaldsen S, Lawrence G, Dawson A, Wiley K, et al. Influenza vaccination during pregnancy: coverage rates and influencing factors in two urban districts in Sydney. Vaccine. 2013;31(47):5557-64.

51. Schwartz AW, Clarfield AM, Doucette JT, Valinsky L, Karpati T, Landrigan PJ, et al. Disparities in pneumococcal and influenza immunization among older adults in Israel: a cross-sectional analysis of socio-demographic barriers to vaccination. Prev Med. 2013;56(5):337-40.

52. Brien S, Kwong JC, Charland KM, Verma AD, Brownstein JS, Buckeridge DL. Neighborhood determinants of 2009 pandemic A/H1N1 influenza vaccination in Montreal, Quebec, Canada. Am J Epidemiol. 2012;176(10): 897-908.

53. Calder K, Bidwell S, Brunton C, Pink R. Evaluation of the Canterbury under18 seasonal influenza vaccination programme. N Z Med J. 2014;127(1398): 19-27.

54. Green HK, Andrews N, Letley L, Sunderland A, White J, Pebody R. Phased introduction of a universal childhood influenza vaccination programme in England: population-level factors predicting variation in national uptake during the first year, 2013/14. Vaccine. 2015;33(22):2620-8.

55. The Joanna Briggs Institute. JBI critical appraisal checklist for studies reporting prevalence data. Adelaide: University of Adelaide; 2017.

56. The Joanna Briggs Institute. Checklist for analytical cross sectional studies. Adelaide: University of Adelaide; 2017.

57. The Joanna Briggs Institute. Checklist for cohort studies. Adelaide: University of Adelaide; 2017.

58. Harris L, Hamilton S, Azvedo L, Olajide J, De Brun C, Waller G, et al. Intermittent fasting interventions for treatment of overweight and obesity in adults: a systematic review and meta-analysis. JBI Database System Rev Implement Rep. 2018;16(2):507-47.

59. Regidor E. Social determinants of health: a veil that hides socioeconomic position and its relation with health. J Epidemiol Community Health. 2006 60(10):896-901.

60. Ahrens W. Commentary: socioeconomic status: more than a confounder? Int J Epidemiol. 2004;33(4):806-7.

\section{Publisher's Note}

Springer Nature remains neutral with regard to jurisdictional claims in published maps and institutional affiliations.

Ready to submit your research? Choose BMC and benefit from:

- fast, convenient online submission

- thorough peer review by experienced researchers in your field

- rapid publication on acceptance

- support for research data, including large and complex data types

- gold Open Access which fosters wider collaboration and increased citations

- maximum visibility for your research: over $100 \mathrm{M}$ website views per year

At $\mathrm{BMC}$, research is always in progress.

Learn more biomedcentral.com/submissions 